\title{
Balazs, Hwang, Jones, and Ross to Chair MRS Spring 2000 Meeting
}

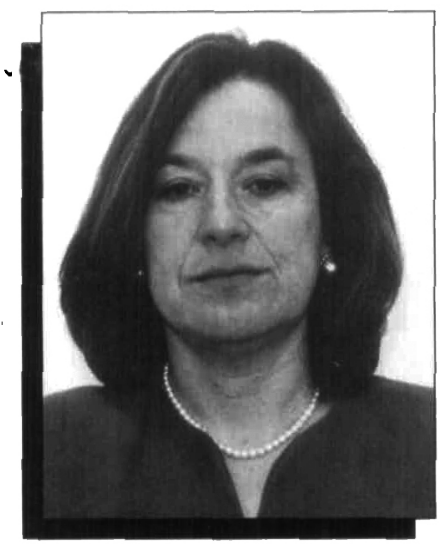

Anna C. Balazs

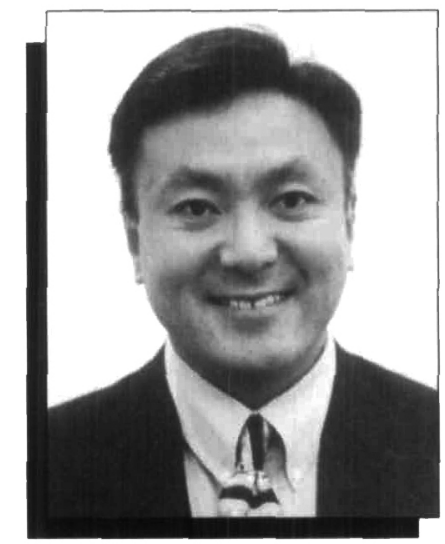

Robert Q. Hwang

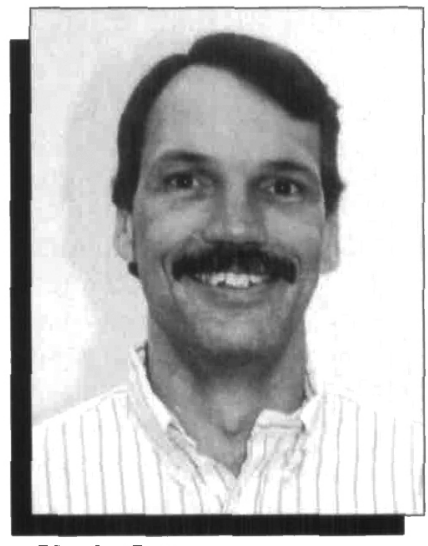

Kevin S. Jones

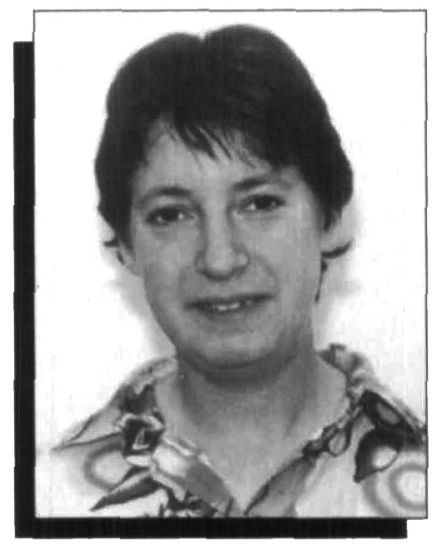

Frances M. Ross
The Materials Research Society 2000 Spring Meeting will be held April 24-28, 2000 in San Francisco, California, at the San Francisco Marriott Hotel and the Argent Hotel. It will be chaired by Anna C. Balazs (University of Pittsburgh), Robert Q. Hwang (Sandia National Laboratories), Kevin S. Jones (University of Florida), and Frances M. Ross (IBM T.J. Watson Research Center).

The meeting will include 34 symposia as well as tutorials, a plenary session and the equipment exhibit. The scientific sessions will include many new and developing areas of materials science as well as some well-established and popular topics. In the area of silicon processing, five symposia will cover areas such as dopant-defect interactions, silicides, dielectrics, and interconnects. Thin film materials and processes will be well represented with nine symposia including areas such as magnetoelectronics, epitaxy of oxides and semiconductors, polycrystalline films, and corrosion. Ten symposia on materials processing and devices will bring us the state of the art in flat-panel displays, wide-bandgap devices, and novel oxide-based devices. Interesting materials such as optoelectronic polymers and thermoelectrics will also be discussed, and MRS will host two new symposia on millimeter wave technology for materials characterization and on direct write technologies. The strong interest of MRS in soft materials will be continued with five symposia in areas such as polymer nanostructures, organic/inorganic hybrids, and the granular state. There will also be two symposia dedicated to materials modeling. For the first time a symposium on materials education, focusing on materials science and engineering education in the new millennium, will be held on the West Coast. Finally, a symposium on analyzing, predicting, and preventing disasters will include many good examples of when materials really matter.

Anna C. Balazs is a professor in the Department of Chemical and Petroleum Engineering at the University of Pittsburgh. Prior to joining the University in 1987, Balazs was a research associate in the Polymer Science and Engineering Department at the University of Massachusetts, and guest scientist at the National Bureau of Standards. She received her $\mathrm{PhD}$ degree in 1981 from the Massachusetts Institute of Technology. Balazs' research involves using statistical mechanics and computer simulations to model polymeric systems. Her current research is focused on modeling the properties of polymer blends and composites, and polymer-surface interactions. She is also interested in the role of polymers in biophysics.

Balazs has won the University of Pittsburgh President's Distinguished Research Award and the Lilly Teaching Fellowship Award. Most recently, she was awarded a National Science Foundation Special Creativity Award. She served on the editorial boards of Macromolecules, Langmuir and Accounts of Chemical Research. In 1997, she was the Guest Editor for the MRS Bulletin issue on "Theory and Simulations of Polymer Surfaces and Interfaces." She currently serves on the editorial board of Macromolecular Theory and Simulations, and is a Specialist Editor for Computer Physics Communications. In 1999, Balazs was the chair of the Polymers West Gordon Research Conference. Balazs is a Fellow of the American Physical Society and is the current chair of the Division of Polymer Physics of the APS. She has over 100 authored or co-authored publications and has written several book chapters.

Robert $Q$. Hwang is a principal member of the technical staff at Sandia National
Laboratories in California. He earned his BS degree in physics from the University of California-Los Angeles in 1981 and his PhD degree from the University of Maryland in 1988 . He was a postdoctorate at Lawrence Berkeley Laboratory and the University of California-Berkeley in 1989 and a Humboldt Fellow at the University of Munich in 1990. He joined Sandia in 1991. Hwang's present interests include atomistic mechanisms in thin film growth and metal alloying, thin film and interfacial strain, corrosion, and nanoscale mechanical properties of metals. He has organized a symposium on epitaxial growth for MRS and he has also been active in the American Physical Society, American Vacuum Society, and The Minerals, Metals \& Materials Society.

Kevin S. Jones is a full professor of Materials Science and Engineering at the University of Florida and an adjunct professor of Electrical and Computer Engineering also at the University of Florida. He received his BS degree in materials science and engineering from the University of Florida in 1980 and his MS (1985) and $\mathrm{PhD}$ (1987) degrees from the University of California-Berkeley. He is also the codirector of the Software and Analysis of Advanced Materials Processing (SWAMP) Center at the university. His current research interests are in the area of ion implantation doping and diffusion during the processing of silicon integrated circuits.

In 1990, Jones was awarded a NSFPresidential Young Investigator Award. He has won the UF teacher of the year award and the faculty excellence award. In 1998 he was given the University of Florida Research Faculty award. He served as the MRS Secretary in 1996-1997 and on the MRS Council, and he has served on or chaired numerous MRS committees. $\mathrm{He}$ was the chair of the 1992 International 
Conference on Ion Implantation Technology. Jones is on the editorial board of Nuclear Instruments and Methods in Physics Research. He has published over 200 papers in the field of defects in semiconductors, written several review chapters on the subject, and edited several books.

Frances $M$. Ross is a research staff member at the IBM T.J. Watson Research Center in Yorktown Heights, New York. She received her PhD degree on transmission electron microscopy of silicon oxides from Cambridge University, and then worked for two years as a postdoctoral
Fellow at AT\&T Bell Laboratories in Murray Hill, New Jersey. During this time she carried out in situ electron microscopy experiments on silicon oxidation and dislocation motion in electronic devices. She then spent four years as a staff scientist at the National Center for Electron Microscopy at Lawrence Berkeley National Laboratory, supervising the operation of the Berkeley atomic resolution microscope and the in situ microscope and developing specimen holders for dynamic experiments on electrochemical etching of silicon and domain motion in ferroelectric materi- als. She moved to IBM in 1997 and has recently been studying epitaxial growth processes of semiconductors and silicides by making real time observations in the microscope. Ross' interests include the application of in situ electron microscopy to understanding reaction mechanisms, in particular semiconductor growth, surface reactions, and electrochemistry, as well as applied aero- and hydrodynamics. She has organized MRS symposia on Materials in Sports and Recreation and Electron Microscopy of Semiconducting Materials.

\section{MRSS Featured Volunteer}

\section{Beth Stadler Chair of the Academic Affairs Committee}

What is your favorite element? I would have to say oxygen because I can't seem to get enough of oxides, probably having nothing to do with my training as a ceramist! I also remember the image of a hungry oxygen atom devouring electrons which produced surface and grain boundary complications in the devices Prof. Tuller discussed in my grad classes at MTT. It may also explain why, when we were looking for a new car, I wanted a Lumina so that I could get vanity plates $\mathrm{Al} 2 \mathrm{OB}$, get it? In fact, I think I'd die without oxygen.

\section{What do you read first in MRS Bulletin?}

I like to read University Chapter News first, if there is a submission for the month.

\section{What was the last book you read? \\ Besides the textbooks I consider for classes and MRS Proceedings, I'm reading Great Expectations by Dickens when I find time.}

\section{What inspired you to be a materials researcher?}

My first inspiration that led to a career as a materials researcher was my crazed high school chemistry teacher Mr. Yanchunas (fondly called Doc Yan). He was great at portraying the mad scientist with a handlebar mustache and goatee and dimples that appeared when he was about to explode something. I hadn't heard of materials science, but I

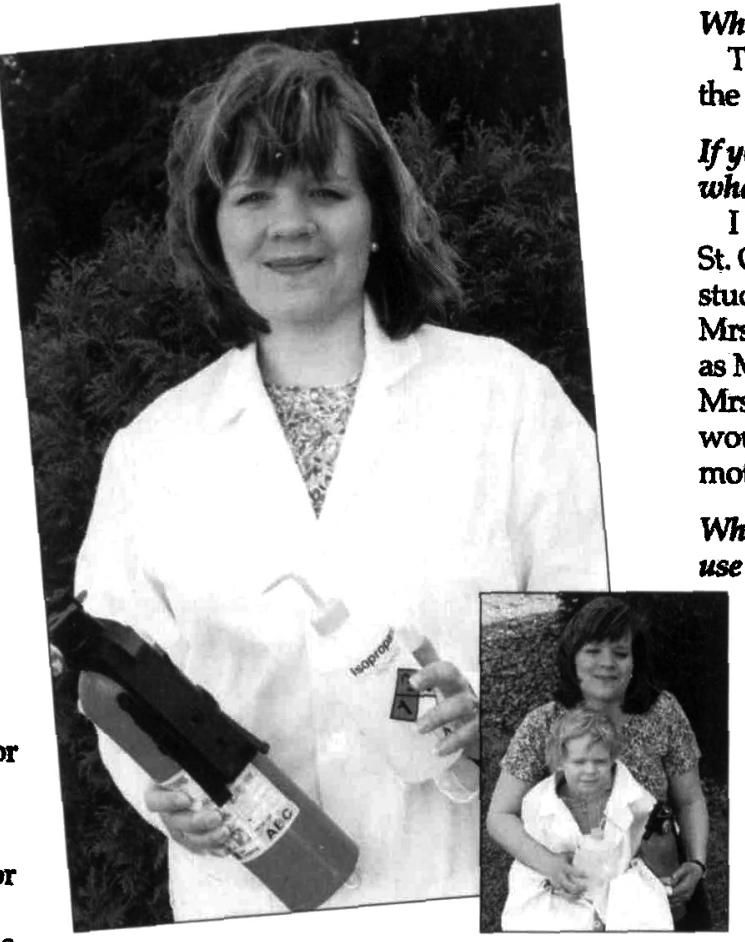

What is your Motto?

The light shown in the darkness, but the darkness has not understood it.

If you were not a materials researcher, what would you be?

I have visited a 4 th grade class at St. Odelias in the Twin Cities. The students misread my name which Mrs. Ruzynski had written on the board as Mrs. Stadler and they called me Mrs. Scientist. I've always thought it would be fun to be a professional promoter of science as Mrs. Scientist, PhD!

\section{What common household item do you} use in your lab?

Scotch Brite ${ }^{\text {tM }}$ removes next to anything from a vacuum chamber almost as well as from a kitchen sink.

Beth Stadler has chaired the Academic Affairs Committee since 1996. Prior to that, she chaired the Special Projects

Subcommittee, served on the

Membership Committee, and coorganized Symposium $M$ on Integrated aimed for inorganic chemistry when I got to Case Western Reserve and the MSE department supplied excellent mentors after that.

\section{What did you first do as an MRS volunteer?}

Slade Cargill asked me to join the Membership Committee as a student rep after I hostessed his visit to our student seminar series. As a first duty, I designed a form for chapters to use in submitting their annual reports. Magneto-Optics-Materials and Devices for the 1998 MRS Spring Meeting. She is a professor at the University of Minnesota.

To contribute to MRS Featured Voluntees, send in your responses to the questions to MRS Bulletin, 506 Keystone Drive, Warrendale, PA 15086-7573; fax 724-7798313, USA; e-mail Bulletin@mrs.org. Include your name, volunteer activity, address, fax, and e-mail. 